\title{
WeldForming: a new inline process combination to improve weld seam properties
}

\author{
T.-E. Adams ${ }^{1}$ (D) - S. Härtel ${ }^{2}$ - A. Hälsig ${ }^{3}$ - B. Awiszus ${ }^{2}$ - P. Mayr ${ }^{1}$ \\ Received: 16 October 2019 / Accepted: 10 January 2020 / Published online: 30 January 2020 \\ (C) The Author(s) 2020
}

\begin{abstract}
The high heat input during fusion welding leads to transformations of the microstructure in the area subjected to welding, mostly resulting in a heterogene crystalline structure and an overall deterioration of the mechanical properties. To reduce the detrimental effect, posttreatment processes which are typically separated from the actual welding process are state of the art. The present work shows the new methodology, WeldForming, which intends to eliminate subsequent treatment processes. The new in-line process combination harnesses the synergies of a welding and a rolling process to ultimately prevent the typical zone formation of the heat affected zone. Experimental investigations combined with a detailed numerical simulation of the coupled welding and forming process indicate the functional proof of the new methodology. The validation of the numerical model is carried out with the aid of temperature profiles, cross sections, and microstructure analysis as well as flow curves determined by upsetting tests on thermomechanical simulation systems.
\end{abstract}

Keywords Property improvement $\cdot$ Hot rolling $\cdot$ Arc welding $\cdot$ Thermomechanical simulation $\cdot$ Numerical simulation $\cdot$ FEM

\section{Introduction}

In fusion welding, energy input is integral to all welding processes, which can lead to extensive transformations and changes of the microstructure and properties of these materials. This applies in particular to steel in the area of the weld metal $[1,2]$. The characteristics of heat input during the welding process will lead to temperature gradients and different cooling rates during the solidification of the weld pool. This can cause an irregular distribution of alloying elements (e.g., segregation) and various microstructural features after solidification may evolve. The resulting weld seam

Recommended for publication by Commission IX - Behaviour of Metals Subjected to Welding

T.-E. Adams

tom.adams@tum.de

1 Materials Engineering of Additive Manufacturing, Technical University Munich, D-85748 Munich, Germany

2 Institute of Machine Tools and Production Processes, Virtual Production Engineering, Technical University Chemnitz, D-09107 Chemnitz, Germany

3 Institute of Joining and Assembly, Welding Engineering, Technical University Chemnitz, D-09107 Chemnitz, Germany microstructure most closely resembles a cast structure. If high heat input welding, e.g., gas metal arc welding (GMAW), is applied to steels, the microstructure of the heat-affected zone (HAZ) close to the fusion line becomes notably coarse, and the toughness of this zone is greatly degraded [3]. Figure 1 shows the characteristic appearance of a weld seam in a cross section.

This can in turn lead to undesirable properties of the whole component, e.g., the joint has inferior strength relative to the unaffected base material [4]. Experiments conducted on highstrength low-alloy steels by Mohandas [5] reveal the effect of the microstructural changes in the HAZ on the overall mechanical properties of the component.

When these steels are exposed to weld thermal cycles, they exhibit softening in a certain region of the HAZ. The degree of softening in the HAZ is thereby a function of the weld thermal cycle, which is a characteristic of the welding process [6]. The softening characteristics also depend on the kinetics of the phase transformations of the steel and are a function of the chemical composition of the steel [7].

Research on a combination of welding and rolling was performed by Yang et al. [8]. Focusing on the prevention of hot cracking in high-strength aluminum alloys, a mitigation of hot cracks by both sided rolling of the weld could be achieved. Extensive work regarding this process combination, 


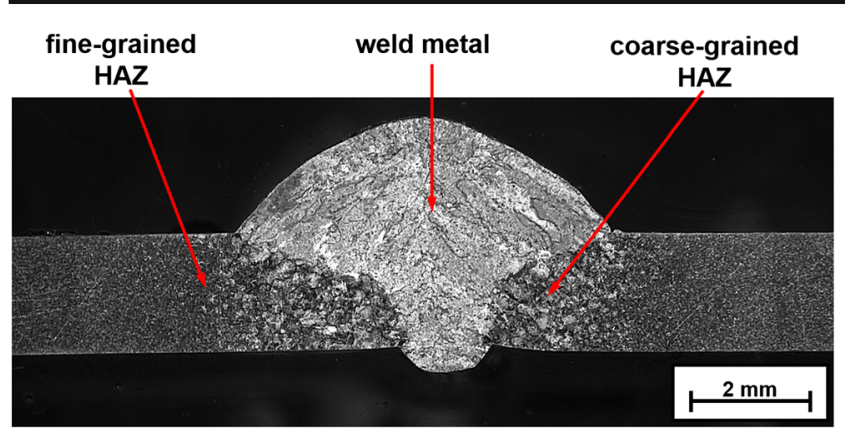

Fig. 1 Macroscopic cross section of a weld seam produced by gas metal arc welding; 2-mm thick sheet S235JR (1.0037)

especially for low carbon steel welds, was done by Coules et al. Analyzing the effect of high pressure rolling on weldinduced residual stresses in [9], it was possible to induce large compressive stresses in and around the weld, leading to a reduction of the normally found tensile stresses. However, the in situ rolling of the weld was found ineffective at reducing residual stresses, due to the subsequent yielding of material during cooling. Further investigations [10] substantiate that when the weld is rolled after welding, the method is capable to change the residual stress distribution and induce large compressive stresses in the weld. As an additional advantage, the fact that the plastic deformation is applied over the entire welding area, rather than just at the surface, which is often the case with peening techniques, is mentioned.

Early investigations by Kondakov [11] regarding microstructural transformations and the resulting property changes using high-temperature rolling were conducted on the titanium alloy (VT 1-1) and an austenitic steel (12Kh18N101). It was found that the rolling of the solidifying weld metal has a complex effect on the properties of the welded joint. A refinement of the microstructure is achieved, the density of the weld metal increases, and the residual displacements are reduced. The more recent work of Coules et al. [12] describes the effect of high pressure rolling on the mechanical properties and microstructure of low carbon steel welds. Tensile, hardness, and impact toughness tests between post-weld rolled, in situ rolled, and not rolled welds were carried out, and the microstructural changes were analyzed.

For in situ and post-weld rolled specimens, an increase in yield strength and hardness in the weld metal and the HAZ could be confirmed. However, for the post-weld specimen, this is achieved due to work hardening. The in situ rolled specimens show a transformation of the typical microstructure into a widespread formation of acicular ferrite, leading to the increase in hardness but also to a slightly decreased impact toughness. The applicability for additive manufacturing, explicit for WAAM steel structures, was investigated by Colegrove et al. [13]. It was found that the interpass rolling reduced the distortion and residual stress. Further a refinement of the grain structure was reached, which corresponds with the investigations of Coules.
The present work shows the newly developed process of WeldForming in which the microstructure optimization can be done continuous. Thermomechanical and numerical simulations were used to facilitate the understanding of the process coupling and to realistically predict the outcome of the process.

\section{Objectives}

The main advantage of the WeldForming process is the targeted adjustment of the microstructure and properties of a welded joint. The intention is to restore the mechanical properties of the joint by allowing a base material like microstructure all over the weld through recrystallization processes.

This is achieved through coupling a welding and a subsequent forming process, directly utilizing the thermal energy from the welding process to initiate recrystallization. The thermal microstructure optimization by means of dynamic, metadynamic, and static recrystallization will be stimulated by the forming process.

In addition to the recrystallization processes, flattening of the weld seam will occur and increase the dynamic strength of the assembly by reducing critical notches. A schematic of the WeldForming process is shown in Fig. 2.

In the newly developed WeldForming process, the postprocessing of the weld seam is carried out in-line-directly after the welding process in one process stage. This means that no additional process steps are necessary, and an additional heating (as in a stress relief treatment) is obsolete. The heat of the welding process is directly utilized; thus, resources in the form of energy and time are conserved.

In addition to coupling both processes, the effect of the initial microstructure (e.g., fine-grained, coarse-grained, all-weld metal) on the recrystallization process will be investigated. The data obtained through experiments is then used for the verification of a numerical simulation of the WeldForming process, and the structure-process-property relationships will be derived.

\section{Experimental setup}

Welding tests are used to obtain a first indication of a suitable welding parameter range and to identify the microstructure

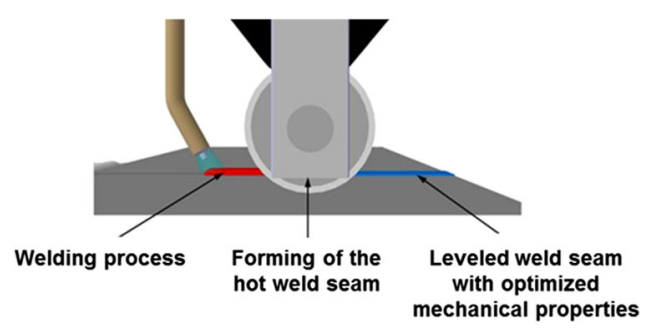

Fig. 2 Schematic of the WeldForming process 
and basic properties of the weld seam. The welding tests are carried out on the normalized steel plate quality EN 10025-2 $\mathrm{S} 235 \mathrm{JR}+\mathrm{N}$ (1.0037) with an overmatching design of the welded connection by the weld filler material G4Sil. The chemical composition of the materials is shown in the following table (Table 1).

Two plates are joined in a butt weld configuration with a sheet-thickness-dependent seam geometry according to DIN EN 9692-1 and with a defined face and root reinforcement.

As welding equipment, a Fronius TransPuls Synergic 5000 CMT R welding power source with connected VR 700 CMT wire feeder is used. The welding parameters are determined for a material thicknesses of $t=4 \mathrm{~mm}$. To ensure the required reproducibility of the results, the welding torch is guided using a 6-axis articulated arm robot.

As a starting point, various welding characteristic curves for arc welding which the welding machine offers were tried out, including the standard CMT and pulsed process settings. Based on these characteristics, optimal settings for welding speed and wire feed rate are determined by means of a full factorial experimental plan. In addition, temperature measurements are carried out to facilitate subsequent material characterization and verification of the process simulation. As shielding gas for the GMAW process, ISO 14175:2008 M21 gas mixture is used (18\% carbon dioxide and $82 \%$ argon).

The first investigations on the recrystallization behavior during hot rolling were carried out in a multistage process. In this decoupled design, the effects and interactions of different parameter and parameter combinations on microstructure development could be investigated more closely. Otherwise, the direct process coupling to the desired WeldForming process would have led to an immense experimental scope due to the high complexity of the combined process.

In this decoupled setup, the welding and forming process are still separated. In the first process step, two plates of S235JR+N steel are joined together in a butt weld configuration using a GMAW welding process. The welded samples are then heated up to different rolling temperatures (see following paragraph) in a chamber furnace. This step is followed by manual transport to the rolling mill. The duo cold rolling mill used has a roller diameter of $235 \mathrm{~mm}$ and can apply a rolling force up to $700 \mathrm{kN}$. The individual rolling process sequence is shown in Fig. 3.

The effect of the temperature on the recrystallization is examined for three temperature levels (i.e., $700{ }^{\circ} \mathrm{C}, 900{ }^{\circ} \mathrm{C}$, and $1100{ }^{\circ} \mathrm{C}$ ). The rolling gap for subsequent hot forming is varied between $4 \mathrm{~mm}$ (completely leveled seam) and $5 \mathrm{~mm}$ to achieve two different degrees of deformation. To determine the specific influence of the different factors (temperature, plastic strain, strain rate, initial microstructure) on the recrystallization behavior and to simulate the coupled process, thermomechanical material simulations are conducted. These are carried out in the form of upsetting tests on the forming and quenching dilatometer Bähr DIL $805 \mathrm{~A} / \mathrm{D}$. The data generated with these experiments, e.g., force-displacement curves, will then be used to determine the recrystallization kinetics and to calculate the necessary flow curves to aid the numerical simulation of the softening effects and later the WeldForming process at large.

\section{Discussion and results}

This chapter describes the different steps of experiments conducted to implement the coupled WeldForming process, beginning with the results of the welding process and ending with the results of the coupled process, including an optimization approach.

\subsection{Welding tests}

The welding results using three different welding characteristic curves are examined with regard to weld seam geometry, seam defects, and spatter tendency. To provide enough material for the forming process, the weld seam should have a face as well as a root reinforcement, which added together should not be more than $80 \%$ of the sheet thickness.

The cold metal transfer (CMT) characteristic curve proved to be unsuitable for welding this material thickness. The heat input of the CMT process was too low to ensure a continuous root reinforcement. Good results were obtained with the standard arc characteristic curve. The weld seam was satisfactory in terms of geometry and structural integrity. In order to reduce the amount of spatter, the weld was produced using spray arc metal transfer. The best welding results have been achieved when using a pulsed process. The corresponding welding parameters are listed in Table 2 .

A typical cross section of the seam produced with the pulsed process is shown in Fig. 4.

The weld seam meets the requirements of a high reinforcement for the later forming process, and in addition, the process
Table 1 Chemical composition of the materials according manufacturer specifications in $\mathrm{wt} \%$

\begin{tabular}{llccccc}
\hline Material & $\mathrm{Fe}$ & $\mathrm{C} \%$ & $\mathrm{Mn} \%$ & $\mathrm{Si} \%$ & $\mathrm{P} \%$ & $\mathrm{~S} \%$ \\
\hline S235JR (base material) & Balance & $<0.2$ & $<1.4$ & - & $<0.045$ & $<0.045$ \\
G4Si1 (filler material) & Balance & 0.08 & 1.5 & 0.9 & $<0.025$ & $<0.025$ \\
\hline
\end{tabular}


Fig. 3 Preliminary multistage process chain of the WeldForming process
Heating of the samples to $\max .1100^{\circ} \mathrm{C}$ (in a chamber furnace)

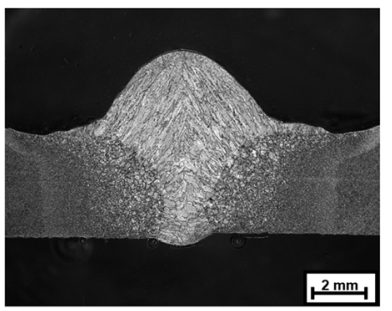

Hot rolling of the weld seam using a Duo-Rolling mill

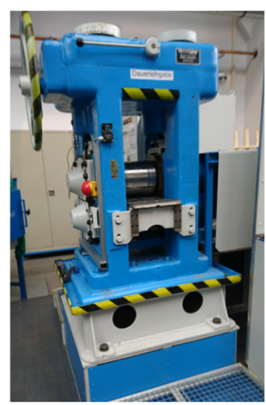

Recrystallized weld seam

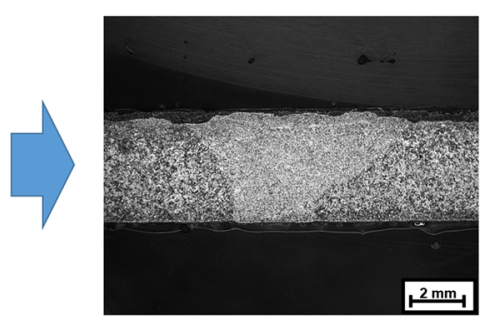

has an extremely low spatter tendency. This process led to the best seam properties, regarding seam geometry, absence of spatter, and defects; additionally no root support was necessary.

Thus, it was decided to use the pulsed process for the implementation of the WeldForming process, with a material thickness of $t=4 \mathrm{~mm}$.

\subsection{Hot rolling}

The recrystallization process is dependent on the temperature, the strain rate, the initial microstructure, and the induced plastic strain. During and shortly after the forming process, different types of softening processes take place depending on the forming conditions (e.g., mean plastic strain, forming temperature, mean strain rate, pause time) [14]. Notably, dynamic recovery and dynamic recrystallization take place during the forming process, after exceeding a critical plastic strain. Furthermore, metadynamic recovery and metadynamic recrystallization take place, which happen after the forming process, with proceeding dynamic softening [14].

Finally, static recovery and static recrystallization occur. These processes take place after the forming, without a previous dynamic softening. The described types of softening are summarized in Fig. 5.

Table 2 Welding parameters for a standard arc and pulsed characteristics at $t=4 \mathrm{~mm}$

\begin{tabular}{lll}
\hline & Standard arc & Pulsed arc \\
\hline Wire feed rate & $10 \mathrm{~m} / \mathrm{min}$ & $9.6 \mathrm{~m} / \mathrm{min}$ \\
Welding speed & $0.7 \mathrm{~m} / \mathrm{min}$ & $0.9 \mathrm{~m} / \mathrm{min}$ \\
Arc correction & $3 \%$ & $5 \%$ \\
Gap & $1 \mathrm{~mm}$ & $1 \mathrm{~mm}$ \\
Voltage & $31 \mathrm{~V}$ & $32 \mathrm{~V}$ \\
Current & $338 \mathrm{~A}$ & $369 \mathrm{~A}$ \\
Power & $10,589 \mathrm{~W}$ & $12,290 \mathrm{~W}$ \\
\hline
\end{tabular}

The global plastic strain in the weld seam can be calculated using Eq. 1.

$\bar{\varphi}=\ln \left(\frac{h_{\text {total }}}{S_{\text {rolling }}}\right)$

The plastic strain is determined from the total height of the weld seam $\left(h_{\text {total }}\right)$ and the roll gap or the remaining height of the weld seam after the forming process $\left(s_{\text {rolling }}\right)$. This corresponds to a global plastic strain of 0.58 in the case of a measured seam height before rolling of $7.12 \mathrm{~mm}$ according to Fig. 4 and a roll gap of $4 \mathrm{~mm}$ and a value of $=0.35$ in the case of a roll gap of $5 \mathrm{~mm}$. Figure 6 shows the simulation results for the distribution of the plastic strain during rolling.

With a roll gap of $4 \mathrm{~mm}$, an increased plastic strain should also be present in the area of the HAZ. This increased plastic strain should therefore also produce corresponding recrystallization phenomena in these areas.

To confirm this assumption, metallographic cross sections are prepared and inspected via light microscopy. In this context, the grain size was determined with the aid of linear

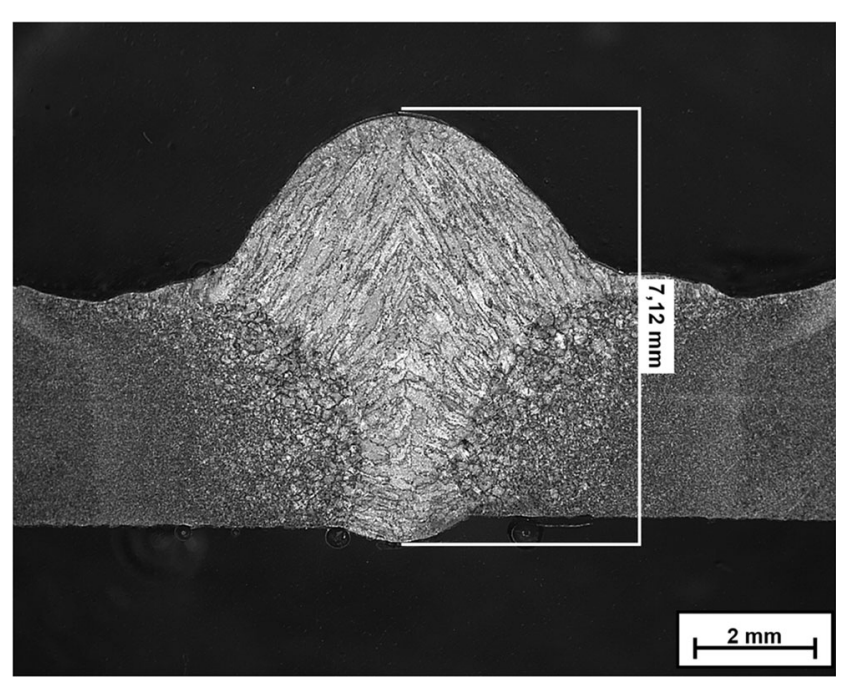

Fig. 4 Cross section of a weld for a 4-mm sheet using the pulsed GMAW process 


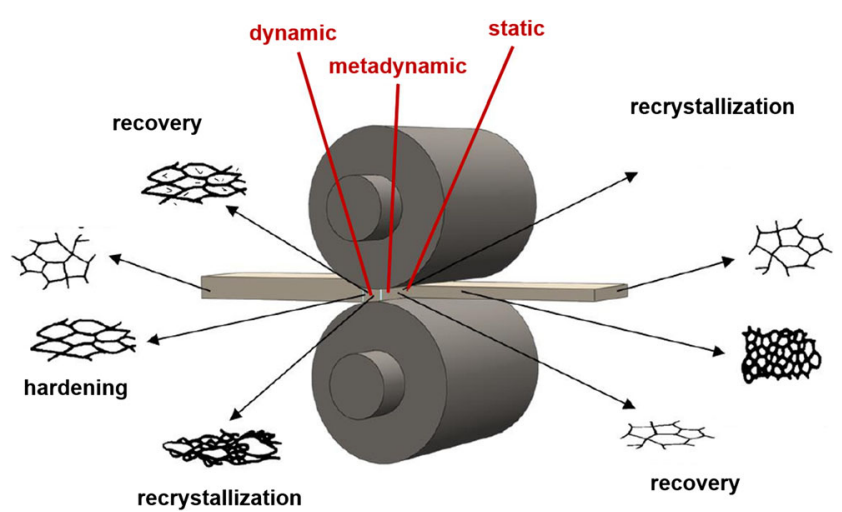

Fig. 5 Softening mechanisms during and after hot rolling [14]

intercept method in different zones of the prepared cross section. An overview of the examined zones is shown in Fig. 7.

In detail, the investigated zones are in the base material (1), the fine-grained HAZ (2), the coarse-grained HAZ (3), the fusion line (4), and the weld metal (5). The microstructure development in connection with the plastic strain applying a rolling gap of $4 \mathrm{~mm}$ or $5 \mathrm{~mm}$ was comparable. Therefore, only the results of the more critical lower plastic strain setup will be discussed.

An overview of the microstructure evolution of the aforementioned zones, which were exposed to different forming temperatures, is shown in Fig. 8.

In the sample formed at $700{ }^{\circ} \mathrm{C}$, no recrystallization phenomena are evident. The specimen shows the expected strainhardened structure. Starting with a fine-grained base material structure (1) with an average grain size of $17 \mu \mathrm{m}$, passing into the fine-grained HAZ (2) with a grain size of $24 \mu \mathrm{m}$. This is adjacent to the coarse-grained HAZ (3) with grain diameters of $56 \mu \mathrm{m}$ and the fusion line (4) with a microstructure that is comparable with a cast microstructure. Lastly, the strainhardened microstructure of the weld with the typical elongated grains follows. In conclusion, a temperature of $700{ }^{\circ} \mathrm{C}$ is not sufficient to initiate recrystallization of the weld metal microstructures.

In the weld seam formed at $900{ }^{\circ} \mathrm{C}$, the grain size of the base material (1) remains unaltered at $14 \mu \mathrm{m}$. In the finegrained HAZ (2) and in the coarse-grained HAZ (3), a finegrained microstructure has developed with an average grain

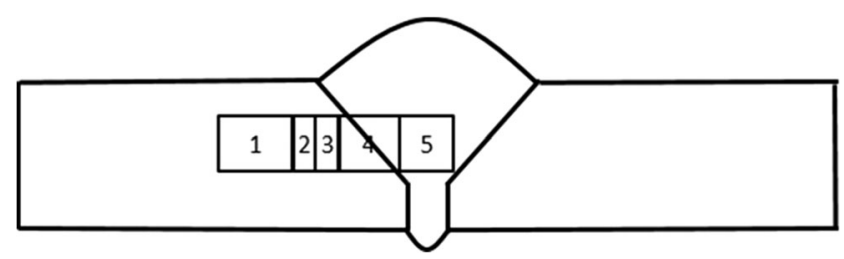

Fig. 7 Different zones of investigation

diameter of $15 \pm 2 \mu \mathrm{m}$. At the fusion line (4), a change takes place from a fine-grained structure into the partially recrystallized structure of the weld metal. In the microstructure of the weld metal, dimly textures of the preceding cast microstructure are still visible. An advanced new grain formation is already apparent, but recrystallization has not been completed yet. A clear delineation of the grains within the weld metal is not yet recognizable everywhere.

The sample formed at $1100{ }^{\circ} \mathrm{C}$ shows a similar microstructure from the base material (1) to the coarsegrained HAZ (3), with a mean grain diameter of $37 \mu \mathrm{m}$. From the fusion line (4), a grain refinement from 30 to $17 \mu \mathrm{m}$ is visible. Parts of the former coarse-grained zone (i.e., brighter sections in the image) already contain a recrystallized structure with a grain diameter of $18 \mu \mathrm{m}$. The weld metal shows a fully recrystallized, fine-grained microstructure with an average grain diameter of $15 \mu \mathrm{m}$. The coarser grain in the base material and the fine-grained $\mathrm{HAZ}$ are a result of the heat treatment to $1100{ }^{\circ} \mathrm{C}$ of the complete assembly. Starting at approximately $950{ }^{\circ} \mathrm{C}$, the temperature range of coarse grain annealing is reached. This leads to a grain coarsening of the complete microstructure of the part. Apart from the weld seam, the rest of the plate does not reach the required plastic strain for a recrystallization of the coarse-grained structure. Only in the area of the transition zone and in the weld metal, a new grain formation takes place.

\subsection{Thermomechanical and numerical simulation}

The thermomechanical simulation follows a systematic testing plan beginning with low forming temperatures $\left(T>700{ }^{\circ} \mathrm{C}\right)$,
Fig. 6 Distribution of the plastic strain in the rolled seam

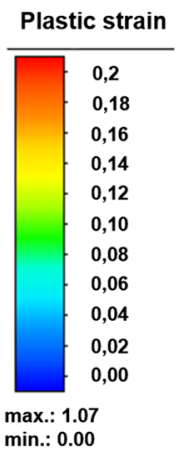

Rolling gap $5 \mathrm{~mm}$

Rolling gap 4 mm
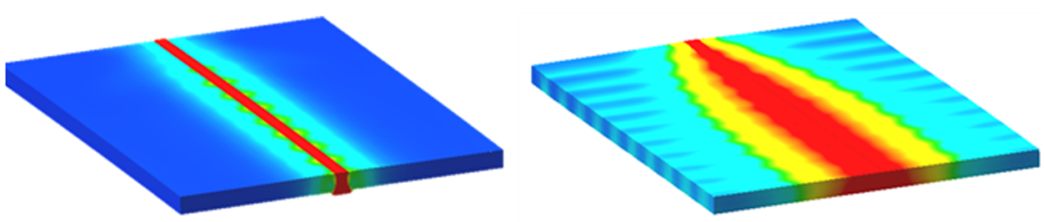


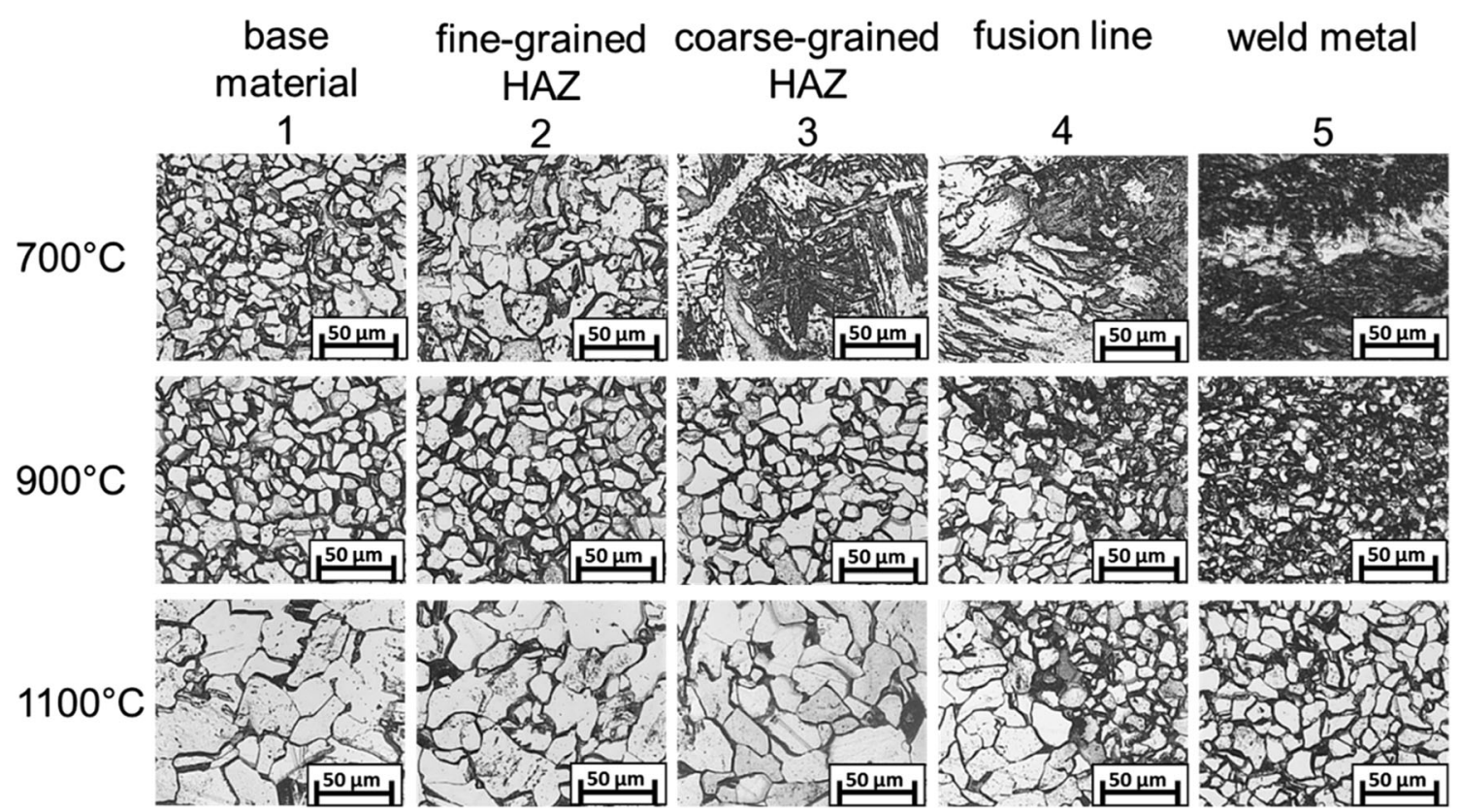

Fig. 8 Microstructure evolution at different forming temperatures $(\bar{\varphi}=0.35)$

strain rates $\left(\dot{\varphi}>1 \mathrm{~s}^{-1}\right)$, and plastic strains $(\bar{\varphi}>0.3)$. These boundary conditions were determined out of preliminary experiments, taking into account the realistic forming conditions in the later process.

To achieve the desired initial microstructures (fine-grained and coarse-grained HAZ, all-weld metal), the specimens are heat-treated in the dilatometer directly prior to the deformation in one temperature cycle, as shown in Fig. 9.

The recorded data (e.g., temperature profile, dilation, force) is used to determine the recrystallization kinetics and to calculate flow curves. This data is then used to validate the forming process in a numerical simulation. A more detailed description of the numerical simulation approach can be found in [15].

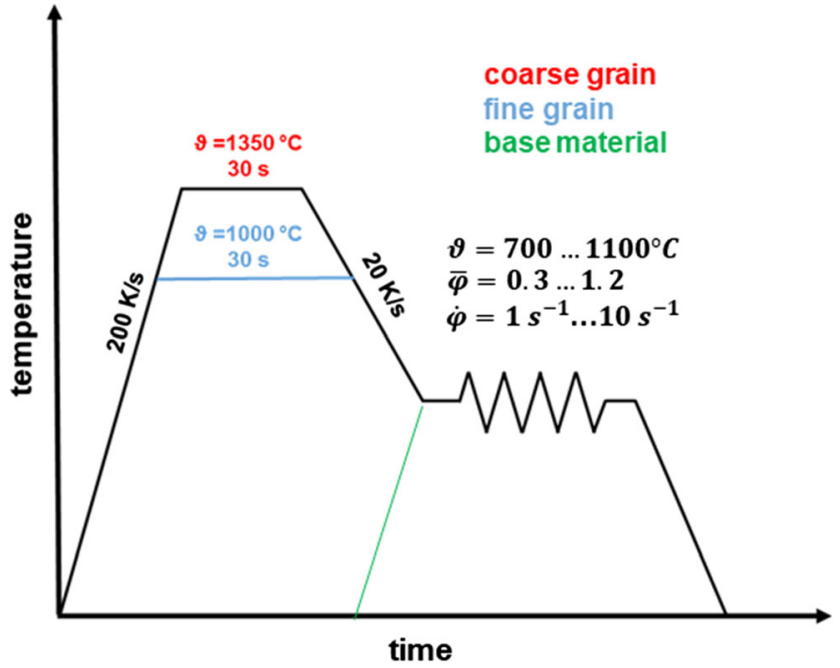

Fig. 9 Temperature/time profile of the thermomechanical simulation
Figure 10 shows a comparison between simulation results and metallography regarding the accumulated fraction of recrystallization. The initial microstructure was in this case a cast-like structure similar to the weld metal structure. The forming in this example was done at three different temperatures with a constant strain rate of $\dot{\varphi}=5 \mathrm{~s}^{-1}$ and a plastic strain of $\bar{\varphi}=0.7$. As forming temperatures $900{ }^{\circ} \mathrm{C}$, $1000{ }^{\circ} \mathrm{C}$, and $1100{ }^{\circ} \mathrm{C}$ were applied. At lower temperatures, no recrystallization phenomena were observed.

The comparison shows that the simulation already gives a reliable prediction of the forming conditions, taking into account the heat dissipation of the forming punches. In the areas of the forming punches, the specimen does not reach the temperature or plastic strain necessary to start the recrystallization process. As a result, no microstructural changes can be observed. The highest fraction of recrystallization is localized in the center of the specimen, where the highest plastic strain is present. These simulation results have been validated by an evaluation of the microscopic images of the microstructure.

The thermomechanical simulations and the derived numerical simulations also confirm the results for the previous mentioned multistage process. It was reconfirmed that that a higher temperature and a higher plastic strain benefits the recrystallization process.

\subsection{Hardness measurements}

To determine the effect of the recrystallization process on the mechanical properties of the welded joints, cross-sectional hardness profiles using HV1 were measured. 
Accumul. fract. of recryst.. [\%]
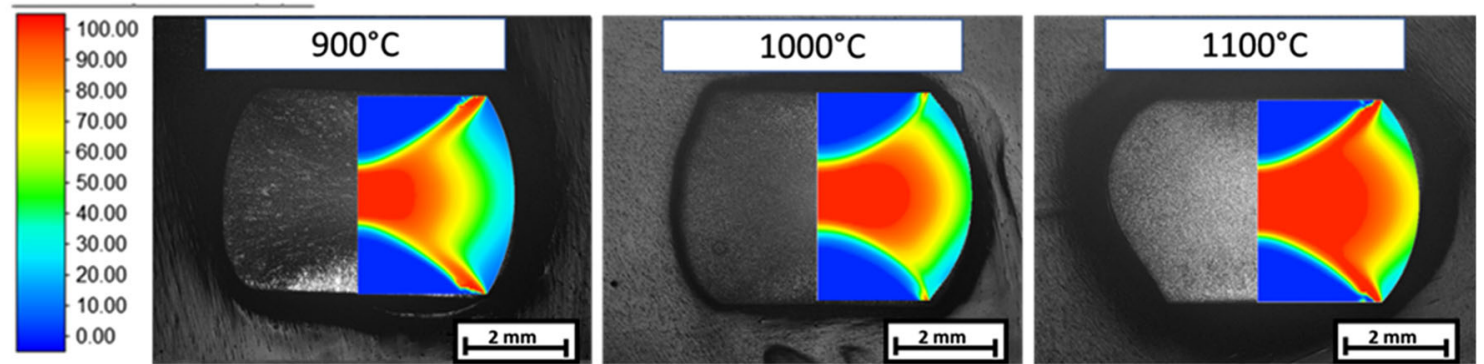

Fig. 10 Comparison of simulation results and metallography for upsetting tests at varying temperatures

Figure 11 shows a comparison of the peak hardness in the weld metal of an as-received weld and three hot-formed specimens.

The evaluation of the formed specimens shows that the hardness difference in the welded joint decreases with a higher forming temperature. Welds formed at $700{ }^{\circ} \mathrm{C}$ do not show any variations in the hardness of the weld seams. At $900{ }^{\circ} \mathrm{C}$, a decrease to $160 \mathrm{HV} 1$ could be measured. At $1100{ }^{\circ} \mathrm{C}$, the hardness drops to around $140 \mathrm{HV} 1$. This can be explained by the amount of recrystallized areas in the weld seam. As described in the previous chapter, a higher forming temperature leads to a higher amount of recrystallization. As a result, a more uniform microstructure in the weld seam is developed which mostly resembles the structure of the base material.

Keeping in mind that the hardness of the base material is around $110 \mathrm{HV} 1$ shows that the hardness peak in the weld seam can be reduced by more than $50 \%$. This way the notch effect resulting out of high hardness differences in the welded joint can be minimized.

\subsection{WeldForming}

On the basis of experimental and numerical investigations, a suitable welding speed could be determined at which a total

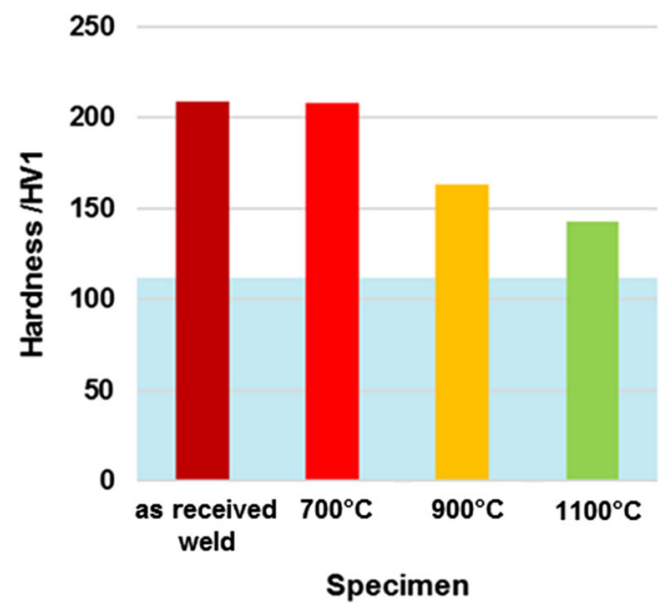

Fig. 11 Comparison of the peak hardness in the weld metal (base material hardness $=$ light blue area) recrystallization of approx. $75 \%$ was numerically predicted. In order to validate this experimentally, the WeldForming process was performed with a welding speed of $0.9 \mathrm{~m} / \mathrm{min}$. The machine setup used is shown in Fig. 12.

The welding torch was integrated in the framework of the rolling mill over an ITEM-construction. To maximize flexibility, the mounting of the welding torch was constructed in such a way that it is adjustable in height and tilt. The intake and outlet area was extended, and the regulation of welding speed is achieved by adjusting the revolutions per minute of the driven rollers.

Figure 13 shows microstructural images of the different stages of a weld-formed sample, done by light microscopy.

It can be seen that the typical cast-like structure of the weld metal (Fig. 13, left) can be transformed into a very finegrained structure by means of recrystallization processes (Fig. 13, right). Thus, the functional principle of the novel methodology of WeldForming is proven. However, there are still elongated grains present in the microstructure, which are caused by the rolling process. This indicates that the recrystallization process is not yet fully completed. This in turn correlates with the preliminary results of the numerical investigations, in which a total fraction of recrystallization of approx. $75 \%$ was calculated.

\subsection{Process optimization}

In order to achieve complete recrystallization in the joining area, the distance between the welding torch and the roller can be reduced in principle. This should result in a higher forming temperature because of the shorter process time and the associated lower heat dissipation; thus, a larger proportion of the microstructure should recrystallize under otherwise identical forming conditions.

In the current configuration, the minimum distance between the welding torch and the roll center is $130 \mathrm{~mm}$ (see Fig. 14, left). A reduction of the minimum distance to $105 \mathrm{~mm}$ can be achieved by tilting the welding torch by $20^{\circ}$ (see Fig. 14, right). This dragging setting leads to a deeper penetration, so that the welding parameters have to be readjusted. The overall result is a significantly lower face reinforcement of the weld (Fig. 14). This results in a lower plastic strain during the rolling process. 
Fig. 12 Experimental setup for the WeldForming process full integration of welding machine in rolling mill framework

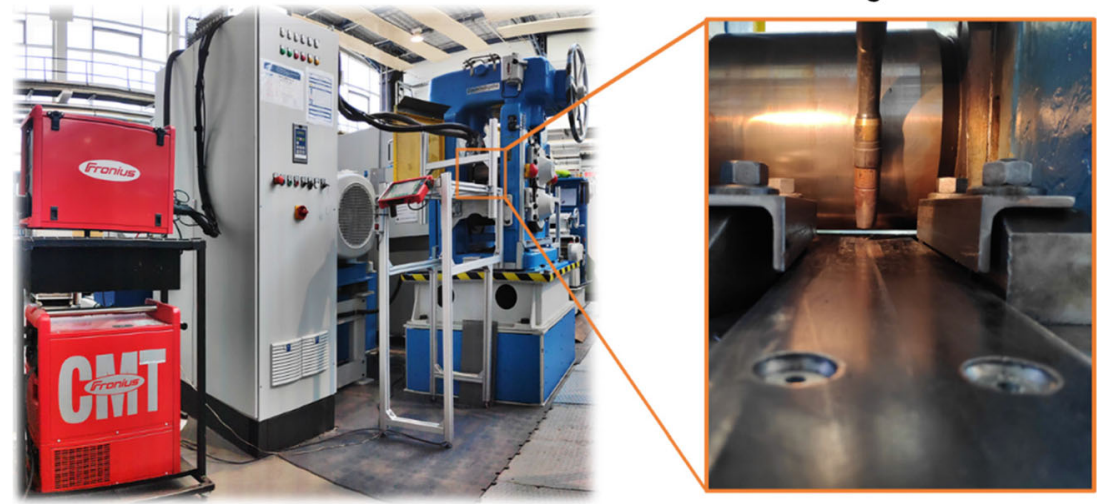

To what extent the tilting of the torch influences the recrystallization behavior was investigated numerically and experimentally.

The numerical simulation of the optimized process showed that despite the lower plastic strain during forming, a higher proportion of recrystallization can be reached. The reason for the increased fraction of recrystallized microstructure is the higher temperature. Table 3 shows the temperatures $50 \mathrm{~mm}$ before and after the roll center.

The reduction of the distance between the welding torch and the center of the roller leads to a significantly higher temperature both before and after the rolling process. Since the recrystallization processes are diffusion-dependent, the increased rolling temperature leads to accelerated recrystallization kinetics and thus to an increased recrystallized fraction. However, the simulation of the optimized process shows a small area in the upper part, with only $50 \%$ recrystallized microstructure (see Fig. 15). The reason for this phenomenon is the low face reinforcement (see Fig. 14). In the area with a recrystallized microstructure of $50 \%$, a plastic strain of approx. 0.3 is achieved in the optimized process. In the standard process, a plastic strain of approx. 0.8 is induced. Nevertheless, it was possible to increase the fraction of recrystallization by using the optimized process, mainly due to the higher temperatures. For this reason, the optimized process setup was implemented experimentally. To verify the simulation light and scanning electron microscopy (SEM) was used. Figure 15 shows corresponding SEM images of the different parts of the seam.

In the upper part of the seam besides the newly formed microstructure, also the acicular structure of the solidifying process is still present, due to the high heat dissipation in the contact area. Investigation preformed with light microscopy confirms an approximate fraction of 50 to $60 \%$

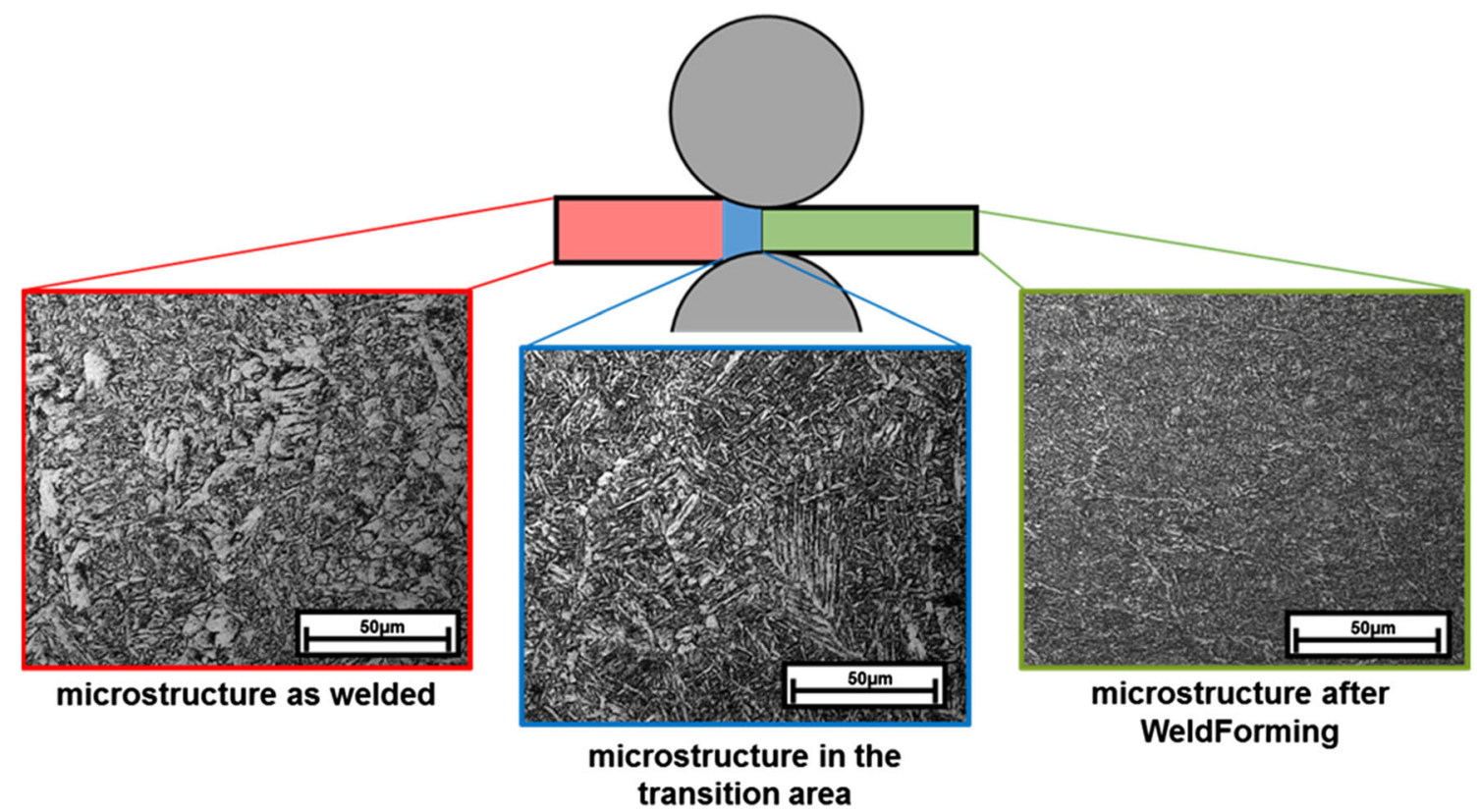

Fig. 13 Microstructure as welded (left), microstructure in the transition area (middle), and microstructure after WeldForming (right) 
Table 3 Ingoing and outgoing temperature for the standard and optimized process

\begin{tabular}{lll}
\hline & Temperature ingoing & Temperature outgoing \\
\hline Standard process & Ca. $1050{ }^{\circ} \mathrm{C}$ & $470{ }^{\circ} \mathrm{C}$ \\
Optimized process & Ca. $1300{ }^{\circ} \mathrm{C}$ & $800{ }^{\circ} \mathrm{C}$ \\
\hline
\end{tabular}

recrystallization. In the lower part of the seam, no acicular structure is present. In this area, a very fine-grained, newly formed microstructure can be found.

\section{Summary}

In this paper, a novel and patented method for altering the microstructure of a welded joint was introduced.

As the first approach, a decoupled process setup was implemented to investigate the effects and interactions of different parameter and parameter combinations on microstructure development. In initial investigations, suitable welding parameters were evaluated, which resulted in a seam geometry leading to the highest plastic strain in the subsequent forming process. The optimal welding parameters, with a welding speed of $0.9 \mathrm{~m} / \mathrm{min}$ and a wire feed rate of $9.6 \mathrm{~m} / \mathrm{min}$, using a pulsed arc for metal active gas welding were implemented. Subsequent hot rolling experiments were conducted variating the plastic strain and forming temperature. Metallographic cross sections of the hotrolled joint showed that the critical plastic strain needed for the recrystallization process at a specific forming temperature was already achieved at a plastic strain of 0.35 .

Based on these results, thermo-physical simulations in the form of upsetting and relaxation tests were performed. The generated data (e.g., temperature profile, dilation, force) was then used to calculate flow curves and recrystallization kinetics in order to describe the material behavior.

Out of this, the first numerical process coupling of a welding and hot rolling process in one single simulation model was developed. The simulation model is based on verified data of the individual processes, taking into account the transformations (recrystallization effects) in the welding area. The influence of the welding speed on the plastic strain, the forming temperature, and the strain rate was analyzed to evaluate the recrystallization effects. Based on the numerical calculations, the WeldForming process was then implemented experimentally.

In order to increase the fraction of recrystallization, the welding torch position was modified from a neutral position ( $90^{\circ}$ angle to work piece) to a dragging position $\left(70^{\circ}\right.$ angle to work piece). With this setup, the forming temperature could be increased, and a nearly complete recrystallization was achieved, despite the lower plastic strain present in this configuration. It was proven that it is possible to transform the cast-like and brittle
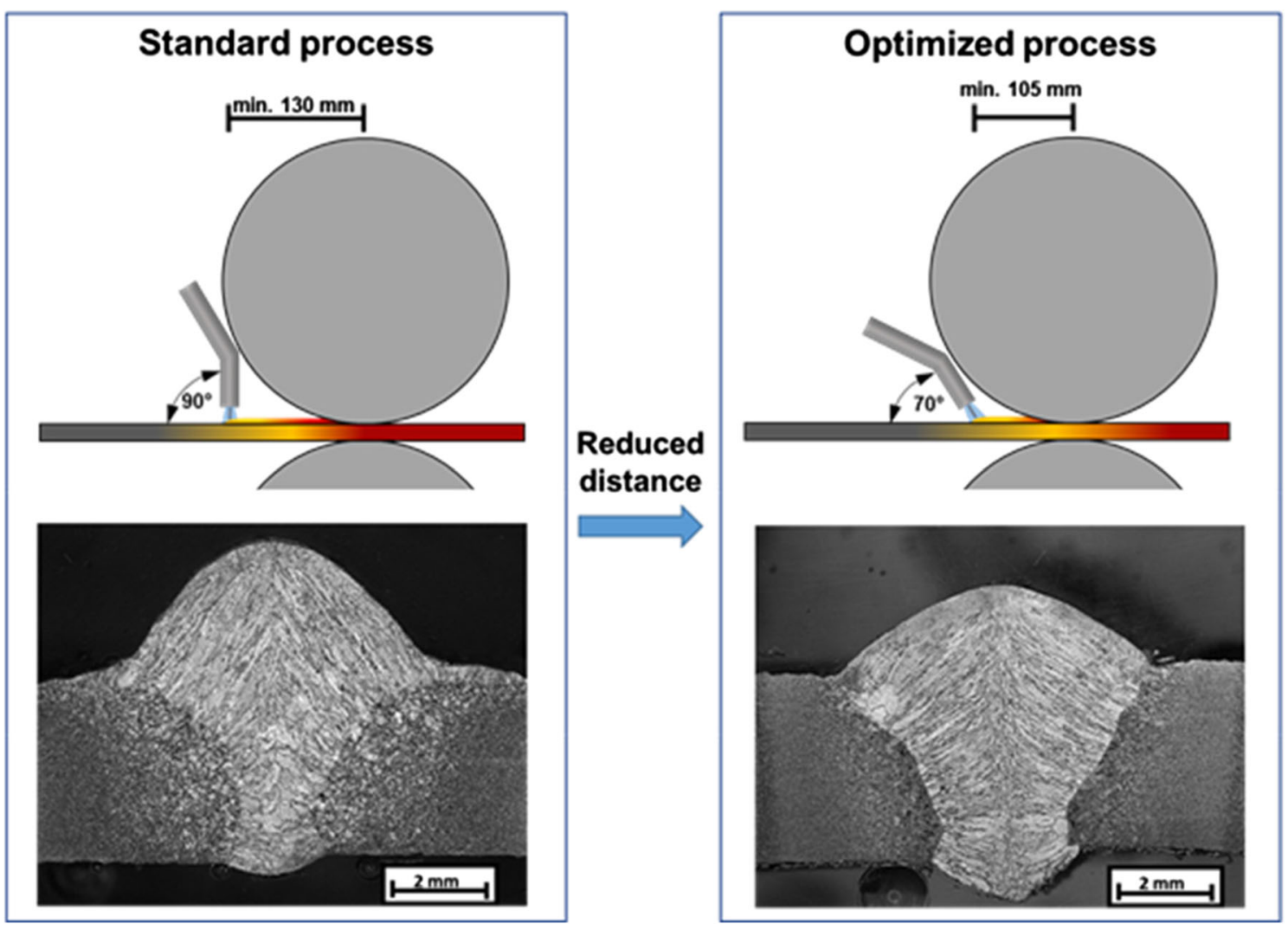

Fig. 14 Welding configuration and resulting seam geometry for standard (left) and optimized process (right) 
Fig. 15 Simulation of the recrystallized fraction of the optimized process and corresponding SEM images

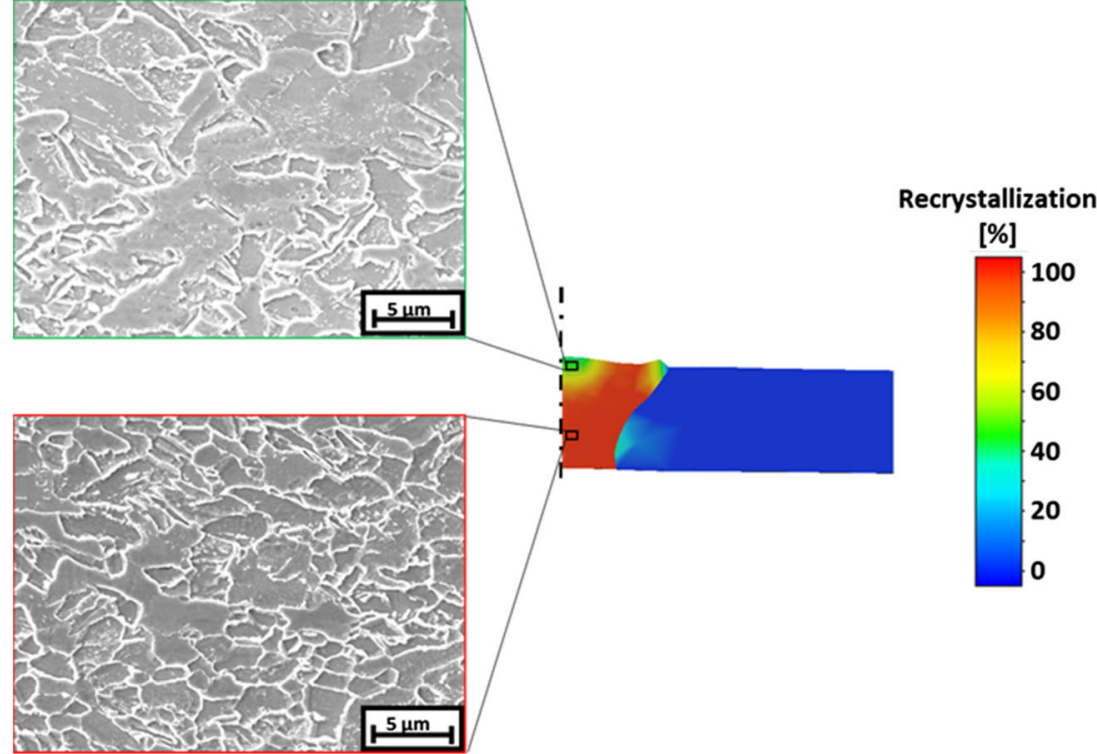

microstructure of the weld metal into a recrystallized grain structure as a result of the WeldForming setup.

Further work will investigate methods to reduce the cooling rate during the forming process, to reduce residual stresses, to stimulate the grain growth, and to achieve a homogeneous microstructure over the whole welding area.

Funding Information Open Access funding provided by Projekt DEAL.

Open Access This article is licensed under a Creative Commons Attribution 4.0 International License, which permits use, sharing, adaptation, distribution and reproduction in any medium or format, as long as you give appropriate credit to the original author(s) and the source, provide a link to the Creative Commons licence, and indicate if changes were made. The images or other third party material in this article are included in the article's Creative Commons licence, unless indicated otherwise in a credit line to the material. If material is not included in the article's Creative Commons licence and your intended use is not permitted by statutory regulation or exceeds the permitted use, you will need to obtain permission directly from the copyright holder. To view a copy of this licence, visit http://creativecommons.org/licenses/by/4.0/.

\section{References}

1. Ashby MF, Easterling KE (1982) A first report on diagrams for grain growth in welds. Acta Metall. https://doi.org/10.1016/00016160(82)90100-6

2. Ion JC, Easterling KE, Ashby MF (1984) A second report on diagrams of microstructure and hardness for heat-affected zones in welds. Acta Metall. https://doi.org/10.1016/0001-6160(84)90176-7

3. Kojima A, Yoshii KI, Hada T, Saeki O, Ichikawa K, Yoshida Y, Shimura Y, Azuma K (2004) Development of high HAZ toughness steel plates for box columns with high heat input welding. Nippon Steel Tech Rep 90

4. Dilthey U (2005) Schweißtechnische Fertigungsverfahren 2 Verhalten der Werkstoffe beim Schweißen. Springer Verlag, Berlin
5. Mohandasa T, Madhusudan Reddy G, Satish Kumar B (1999) Heataffected zone softening in high-strength low-alloy steels. J Mater Process Technol. https://doi.org/10.1016/S0924-0136(98)00404-X

6. Madhusudhan Reddy G, Mohandas T (1996) Ballistic performance of high strength low alloy steel weldments. J Mater Process Technol. https://doi.org/10.1016/0924-0136(95)02041-1

7. Lundin CD, Gill TPS, Qiao CY (1989) Heat affected zones in low carbon micro alloyed steels. Proceedings on Recent Trends in Welding Science and Technology ASM International

8. Yang YP, Dong P, Tian X, Zhang Z (1998) Prevention of welding hot cracking of high strength aluminum alloys by mechanical rolling. ASM Proceedings of the International Conference: Trends in Welding Research

9. Coules H, Colegrove P, Cozzolino LD, Wen SW, Ganguly S, Pirling T (2012) Effect of high pressure rolling on weld-induced residual stresses. Sci Technol Weld Join:17. https://doi.org/10. 1179/1362171812Y.0000000021

10. Coules H, Colegrove P, Cozzolino LD, Wen SW, Kelleher J (2013) High pressure rolling of low carbon steel weld seams: part 2 - roller geometry and residual stress. Sci Technol Weld Join 18. https://doi. org/10.1179/1362171812Y.0000000080

11. Kondakov TF (1988) High temperature rolling in welding butt joints. Weld Int. https://doi.org/10.1080/09507118809447463

12. Coules H, Colegrove P, Cozzolino LD, Wen SW (2012) High pressure rolling of low carbon steel weld seams: part 1 - effects on mechanical properties and microstructure. Sci Technol Weld Join 18. https://doi.org/10.1179/1362171812Y.0000000079

13. Colegrove P, Coules H, Fairman J, Martina F, Kashoob T, Mamash H, Cozzolino LD (2013) Microstructure and residual stress improvement in wire and arc additively manufactured parts through high-pressure rolling. J Mater Process Technol 213. https://doi.org/ 10.1016/j.jmatprotec.2013.04.012

14. Ullmann M (2014) Rekristallisationsverhalten von geglühtem AZ31Gießwalzband beim Warmwalzen, Dissertation, TU Bergakademie

15. Härtel S, Adams T-E (2019) WeldForming - a new inline process combination for the improvement of weld seam properties. IOP Conference Series: Materials Science and Engineering. https://doi. org/10.1088/1757-899X/480/1/012017

Publisher's note Springer Nature remains neutral with regard to jurisdictional claims in published maps and institutional affiliations. 